\title{
Mapas conceituais no ensino de física como estratégia de avaliação
}

Conceptual maps in physics teaching as a strategy of evaluation

\author{
M.V. Souza Junior ${ }^{1 *}$; V.C.C. Célioㅇ, S.C.O. Nogueira², A.F. Martins² ${ }^{2}$ K.H.G. \\ Freitas $^{3}$, F.F. de Sousa ${ }^{1}$ \\ ${ }^{1}$ Instituto de Ciências Exatas, Universidade Federal do Sul e Sudeste do Pará, CEP: 68505-080, Marabá-PA, Brasil \\ ${ }^{2}$ Faculdade de Química, Universidade Federal do Pará, CEP: 66075-110, Belém-PA, Brasil \\ ${ }^{3}$ Campus de Ananindeua, Universidade Federal do Pará, CEP: 66.075-110, Ananindeua, PA, Brazil
}

*juniorvilar09@gmail.com

(Recebido em 19 de dezembro de 2016; aceito em 30 de dezembro de 2016)

\begin{abstract}
Considerando as várias dificuldades dos alunos de Ensino Fundamental em aprender conceitos de físicos, nota-se a necessidade de elaborar novas estratégias de ensino visando minimizar tais dificuldades e, ao mesmo tempo, despertando interesse do aluno para o estudo de Física. Como proposto por Joseph Novak, o mapa conceitual é uma ferramenta utilizada como recurso para alcançar a aprendizagem significativa, contribuindo à construção hierárquica dos conceitos a partir dos conhecimentos prévios dos alunos. Por isso, o presente trabalho foi realizado para abordar a utilização de mapas conceituais como instrumento de avaliação durante o processo de ensino e aprendizagem sobre conceitos de ondas, som e luz. Os mapas conceituais foram elaborados e aplicados aos alunos de uma turma do $9^{\circ}$ ano de uma escola pública da cidade de Marabá (Pará). A análise foi baseada em critérios, como segue: conceitos sobre o conteúdo, hierarquização, relações entre os conceitos e clareza durante a leitura do mapa conceitual. A partir dessa análise, observou-se inicialmente que os alunos apresentam grandes dificuldades, e elas diminuem à medida que os mapas conceituais são refeitos. Os resultados deste trabalho permitiram constatar, também, que a ferramenta de mapa conceitual pode ser usada como estratégia de avaliação, bem como observar as limitações e as potencialidades que os alunos apresentam sobre a aprendizagem dos conceitos propostos. Além disso, conclui-se que os mapas possibilitam melhor aprendizagem e valorizam os conhecimentos pré-existentes dos alunos.

Palavras-chave: Ensino de Física, Mapas conceituais, Estratégia de avaliação
\end{abstract}

Considering the various difficulties of Elementary School students for learning physical concepts, is perceived a need to elaborate new teaching strategies aiming to minimize such difficulties as well as wakening interest of the student to the physics study. As proposed by Joseph Novak, the concept map is a tool used as a resource to achieve meaningful learning, contributing thus to hierarchical construction of concepts from students' previous knowledge. Therefore, the present paper was carried out to approach about the utilization of concept maps as an evaluative tool during the teaching and learning process on concepts of waves, sound and light. The concept maps were elaborated and applied to the students of $9^{\text {th }}$ year of a public school from Maraba city. The analysis was based in criteria, as follows: concepts about content, hierarchization, relationships between concepts and clarity during the reading of the concept map. From this analysis, it was initially observed that students present great difficulties, and they decrease as concept maps are redone. The results of this work also showed that the concept map tool can be used as an evaluative strategy, as well as to observe the limitations and potentialities that the students present on the learning of the proposed concepts. In addition, it is concluded that maps allow better learning and value their pre-existing knowledge.

Keywords: Teaching of physics, Concept maps, Strategy of evaluation

\section{INTRODUÇÃO}

Em busca de um novo modelo de aprendizagem surgem novos modelos que tentam justificar o funcionamento de nossa mente para entender o que pode ou não ser aprendido. Valeria [1] reporta em seu livro "Teorias da Aprendizagem", que o ato de aprender é muito complexo, pois 
não só envolvem somente os sentidos, mas também sistemas mais complexos como o interesse, a memória e a atenção. Muitos são os teóricos que discutem a teoria da aprendizagem. Cada um deles define e aponta os principais focos que devem ser analisados e para o entendimento do assunto foram criadas diversas teorias abordando o tema.

Diante disso, é necessário discutir sobre a disciplina de física que é uma das ciências na qual a grande maioria dos alunos apresenta dificuldade durante o processo de ensino e aprendizagem. Tal problema, talvez esteja associado à memorização dos assuntos e fato de os educadores utilizarem apenas a prova escrita como único método de avaliação da aprendizagem. Os educadores geralmente às vezes não se preocupam, em fazer uma analogia da aplicabilidade das teorias aprendidas nos cursos superiores com metodologias, ações educativas atrativas e eficientes no processo de ensino aprendizagem, bem como adaptando os conceitos estudados em sala de aula para a realidade que se faz presente no cotidiano do aluno. Tal atitude provavelmente ajudaria na tentativa de melhorar a assimilação do conteúdo abordado em sala de aula.

Segundo Alberto [2], a teoria da comparação de David Paul Ausubel [3], ou teoria da aprendizagem significativa é uma teoria cognitivista e procura esclarecer os mecanismos internos que ocorrem na mente humana com relação ao aprendizado e a estruturação do conhecimento pré-estabelecido.

A abordagem deste trabalho é baseada na teoria de aprendizagem de David Ausubel [3], a qual apresenta teorias para processo de ensino-aprendizagem, e usar-se-á os Mapas de conceitos ou conceituais de Joseph Novak [4] como ferramenta-didática-estratégica facilitadora dessa aprendizagem. A pesquisa é de natureza teórica e prática, e optou-se pela metodologia da análise qualitativa dos mapas inicias e dos refeitos, onde descreve o desenvolvimento e as características dos mapas elaborados pelos discentes.

\section{TEORIA DA APRENDIZAGEM SIFNIFICATIVA}

A única maneira de se aprender e consequentemente adquirir conhecimento é estudando, observando ou por meio da experiência. No entanto, o conhecimento prévio, pode servir de "ancoradouro" para novos conhecimentos e, ao mesmo tempo, pode funcionar como obstáculo epistemológico [5], o que está associado àqueles sujeitos imersos na ignorância, porque tomam os conhecimentos primários como verdadeiros e, consequente, rejeita as novidades postas à eles.

A teoria de aprendizagem, segundo Moreira [6], é "um processo através do qual uma nova informação se relaciona, de maneira substantiva e não arbitrária, a um aspecto relevante da estrutura cognitiva do indivíduo". Skinner considerou o professor como um dos principais elementos para a aprendizagem dos sujeitos. Esta ideia se torna ainda mais explicita quando o autor diz que "ensinar é o ato de facilitar a aprendizagem; quem é ensinado aprende mais rapidamente do que quem não é" [7].

Assim, o material desenvolvido pelo professor deve promover ampla gama de recursos que permita ao estudante entrar em contato com os problemas, suas possíveis soluções e forma de praticá-las, podendo assim, construir conceitos científicos [8].

No ensino, o que se pretende é que o aluno atribua aos novos conhecimentos, veiculados pelos materiais de aprendizagem, os significados aceitos no contexto da matéria de ensino [6].

\subsection{APRENDIZAGEM SIGNIFICATIVA E MECÂNICA}

Segundo Ausubel [3], a aprendizagem se torna muito mais significativa à medida que o novo conceito é incorporado às estruturas de conhecimento do aprendiz, e adquire significado para ele a partir da relação com seu conhecimento prévio. Uma vez ligados, os conhecimentos tendem a não serem esquecidos dentro de outros conjuntos de conhecimento que o mesmo possui.

A aprendizagem significativa está relacionada à maneira de organizar o processo de aprendizagem e estruturá-lo em torno da aprendizagem por recepção/aprendizagem por descoberta, onde se refere à forma como o aluno recebe o conteúdo que deve aprender [9]. $\mathrm{O}$ autor Moreira [6] afirma que, a "Aprendizagem significativa implica dar significados ao novo 
conhecimento por interações com significados claros, estáveis e diferenciados, previamente existente na estrutura cognitiva do aprendiz".

Para Novak [4], a aprendizagem significativa ocorre quando uma nova informação é relacionada com conceitos já existentes na estrutura cognitiva do sujeito, em contra partida, a aprendizagem mecânica acontece quando o indivíduo não relaciona essa mesma informação com conceitos já existentes em seu cognitivo, portanto sendo apenas memorizada e apagada em seguida. Moreira [6] esclarece que,

“a aprendizagem por recepção e aprendizagem por descoberta não constituem uma dicotomia. Assim como há um contínuo entre aprendizagem mecânica e aprendizagem significativa, há outro entre aprendizagem por recepção e aprendizagem por descoberta".

O conteúdo assimilado pela estrutura cognitiva encontra-se na forma hierárquica, onde os conceitos mais amplos se sobrepõem a conceitos com menor poder de extensão. Caso isso não ocorra, o conhecimento se torna mecânico ou repetitivo, uma vez que não se atribuiu significado, e o novo conteúdo passa a ser armazenado isoladamente ou por meio de associações arbitrárias na estrutura cognitiva.

Segundo Romero Tavares [10], a aprendizagem mecânica induz o aluno a ser esforçar menos, a aprendizagem memorística é volátil, com um grau de retenção baixíssimo na aprendizagem de médio e longo prazo, o que justifica o alto índice de déficit entre os alunos.

Ausubel [3] refere-se à estrutura cognitiva como o conteúdo total das informações, fatos, conceitos, princípios etc., sendo esta altamente organizada e hierarquizada, na qual elementos menos importantes são incorporados a conceitos maiores, mais gerais e inclusivos. Aprendizagem é definida como sendo o processo pelo qual o novo conteúdo se organiza e se integra à estrutura cognitiva [11].

\subsection{ENSINO DE FÍSICA}

As dificuldades e problemas que afetam o sistema de ensino em geral e particularmente o Ensino de Física não são recentes e têm sido diagnosticados há muitos anos, levando diferentes grupos de estudiosos e pesquisadores a refletirem sobre suas causas e consequências [12]. A educação brasileira é marcada por um conjunto de deficiências e questões problemáticas, que requerem mudanças, e com relação às ciências naturais o problema é ainda mais grave [13], pois está ligado ao fato da escola empregar a forma tradicional que proporciona separações na área do conhecimento. Como um exemplo, pode-se citar o que acontece no Ensino de Física quando os conceitos são repassados aos alunos em forma de blocos (Mecânica, ótica, eletricidade, etc.), no qual essas divisões impedem os alunos que reconheçam como esses conhecimentos podem ser relacionados, tornando assim, difícil uma discussão compreensiva e produtiva sobre a Ciência.

O Ensino de Ciências continua sendo uma caricatura muito pobre daquilo que o conhecimento científico requer na formação dos estudantes. E os conceitos apresentados na disciplina de Física baseiam-se em fórmulas e definições desvinculadas das necessidades da formação dos estudantes e de conhecimentos científicos relevantes [14].

No contexto escolar, alunos sentem-se aterrorizados pelo Ensino de Física. Muitos acreditam que a disciplina é algo impossível de se aprender sem notar que a Física é uma ciência que caminha lado a lado de fenômenos que ocorrem diariamente no seu ambiente. Provavelmente, isso ocorre pelo simples fato de distorcerem o ensino com apresentações de livros contendo conceitos, leis e fórmulas matemáticas e exercícios repetitivos que apenas estimulam a memorização e automatização.

Para tal afirmação, Libânio [15] torna claro que a atividade de ensinar, na educação brasileira, é vista comumente, como um modo de transmissão da matéria aos alunos, realizações de exercícios repetitivos, memorizações e definições de fórmulas e conceitos. 


\begin{abstract}
“(...) O professor passa a matéria, os alunos escutam, respondem o interrogatório do professor, para reproduzir o que está no livro didático, praticam o que foi passado em exercícios de classe e decoram tudo para a prova".
\end{abstract}

Portanto, diversos fatores têm contribuído para o alto índice de reprovação e desinteresse dos alunos pela disciplina de Física no ensino médio, sendo que uma das principais causas para tal quadro preocupante é a desarticulação dos conteúdos ensinados com a realidade e cotidiano da maioria dos alunos.

\title{
2.3 MAPAS CONCEITUAIS: CONCEITOS E CARACTERÍSTICAS
}

Os mapas conceituais foram desenvolvidos em 1972, dentro do programa de pesquisa realizado por Novak [16] na Universidade de Cornell, no qual ele buscou acompanhar e entender as mudanças na maneira como as crianças compreendiam a ciência. Os mapas conceituais são ferramentas gráficas para a organização e representação do conhecimento. Eles incluem conceitos, geralmente dentro de círculos ou quadros de alguma espécie, e relações entre conceitos, que são indicadas por linhas que os interligam. As palavras sobre essas linhas, que são palavras ou frases de ligação, especificam os relacionamentos entre dois conceitos [11].

O aluno ao recriar o mapa deve deixar claro no mapa conceitual quais os conceitos considerados importantes sobre o conteúdo e quais os peculiares. Os mapas conceituais revelam com cada um dos aprendizes uma estrutura do seu conhecimento em relação ao conteúdo em estudo. Por isso, não existe apenas um único mapa correto, mas sim infinitas possibilidades de hierarquizar e relacionar os conceitos em foco [17]. O ideal é que mapas conceituais sejam elaborados a partir de alguma questão particular que procuramos responder, o que denominamos questão focal e a partir dela buscar a compreensão por meio da organização do conhecimento na forma desse mapa, provendo assim o contexto para ele [11].

Mapas conceituais não podem ser confundidos com organogramas ou diagramas de fluxo, pois não apresentam uma sequência, temporalidade ou uma direção e nem hierarquias organizacionais, como também, não podem ser confundidos com mapas mentais que são considerados associacionistas, onde não se preocupam com as relações entre os conceitos, incluem coisas que não são consideradas conceitos e não seguem uma hierarquia. Mapas conceituais são diagramas de significados, de relações entre conceitos e hierarquias, se for 0 caso. Assim também, como não classificam conceitos, e sim relacionam uns com os outros [6].

Os mapas conceituais podem ser usados para se obter uma visualização da organização conceitual que o aluno atribui a um dado conhecimento. Trata-se basicamente de uma técnica não tradicional de avaliação que busca informações sobre significados e relações significativas entre conceitos-chave do conteúdo de ensino segundo o ponto de vista do aluno [6].

\subsection{MAPAS CONCEITUAIS COMO INSTRUMENTO AVALIATIVO DA APRENDIZAGEM}

Escolher uma ferramenta de avaliação é um grande desafio para professores devido à diversidade de objetivos de aprendizagem, a diversidade de aspectos que evidenciam a aprendizagem, a diversidade de ferramentas e recursos disponíveis e os vários aspectos a serem avaliados [18].

Para a utilização dos mapas conceituais como ferramenta de avaliação é necessário que os alunos se familiarizem com a técnica, isto é busquem aceitar o novo método, e o professor aceite a tarefa de avaliar os estudantes, por meio de um instrumento subjetivo e que não possui a comodidade da utilização do gabarito para orientá-lo no processo da correção. O mapa conceitual utilizado enquanto instrumento avaliativo tem objetivo de coletar informações acerca da estruturação edificada pelo aluno para um conjunto de conceitos, sendo assim um tipo de avaliação formal.

O professor pode avaliar os mapas conceituais dos aprendizes de duas maneiras segundo Turns e Atman [18], 
“a) Através da análise individual do mapa conceitual construído pelo aluno, verificando características como, por exemplo, o número de conceitos representados, o número de ligações entre conceitos, o número de ligações cruzadas, o número de níveis hierárquicos e o número de exemplos citados;

b) Através da comparação do mapa do aluno com um mapa desenvolvido por um especialista."

A partir de um mapa conceitual elaborado sobre um conteúdo em foco, o professor pode extrair várias informações podendo ser utilizadas para ajudar o aluno durante o processo de construção do conhecimento, pois, através do mapa é possível, por exemplo, analisar se o aluno apresenta algum conceito equivocado, sua habilidade de organização e estruturação. Além disso, a profundidade que o aluno apresenta sobre a mobilização de um conceito, se faz diferenciação progressiva e reconciliação integrativa. São vários aspectos que podem ser extraídos a partir de sua análise, e isto, ajudará o professor a refletir como está o processo de construção do conhecimento dos alunos, em qual nível de aprendizagem cada aluno se encontra.

\section{MATERIAIS E MÉTODOS}

Este trabalho foi desenvolvido levanto em conta a natureza teórica e prática, pois foram analisados qualitativamente os mapas inicias e os refeitos, onde descreve o desenvolvimento e as características dos mapas elaborados pelos discentes e a aplicabilidade do mapa conceitual, estruturado em acordo com a teoria da aprendizagem significativa de Ausubel [3].

\subsection{COLETA DE DADOS}

O presente estudo foi realizado em uma turma do $9^{\circ}$ ano da escola municipal de Ensino Fundamental "Dr. José Cursino de Azevedo" localizada na cidade de Marabá-Pará. O total de alunos participantes foram 28 alunos, sendo que deste universo, 3 (três) deles foram selecionados para integrar a categoria dos sujeitos de pesquisa. A seriedade e o interesse em desenhar os mapas, foram os critérios de seleção.

\subsection{PROCESSO DE ELABORAÇÃO DO MAPA}

Durante o processo de construção do conhecimento, ocorreram em várias etapas aonde os alunos elaborarem seus mapas conceituais, levando em conta tanto a investigação das concepções prévias dos estudantes sobre o conteúdo de Ondas, bem como a intervenção didática para a reelaboração dos referidos mapas. $\mathrm{Na}$ Tabela 1 , constam as etapas realizadas pelos os alunos, onde os primeiros mapas construídos foram denominados de sondagem, pois, por meio deles analisaram-se as concepções prévias dos estudantes sobre o assunto proposto. No primeiro momento em sala de aula, foram expostos conceitos referidos as características dos mapas conceituais, a forma de organização e termo de ligação. Em seguida, foi explicou-se aos alunos à diferença entre: mapa conceitual e mapa mental.

Tabela 1: Descrição sobre o processo de elaboração dos mapas

\begin{tabular}{c|l}
\hline \hline Etapas & \multicolumn{1}{|c}{ Descrição } \\
\hline $\mathbf{1}^{\circ}$ & $\begin{array}{l}\text { Aula sobre mapa conceitual: Estrutura; Hierarquização; } \\
\text { Preposição. }\end{array}$ \\
\cline { 2 - 2 } $\mathbf{2}^{\mathbf{o}}$ & $\begin{array}{l}\text { Elaboração do primeiro mapa sobre o conteúdo Ondas } \\
\text { (sondagem). }\end{array}$ \\
\cline { 2 - 2 } $\mathbf{3}^{\circ}$ & $\begin{array}{l}\text { Intervenção didática: uma aula de revisão sobre o conteúdo } \\
\text { de } \text { Ondas. }\end{array}$ \\
\cline { 2 - 2 } $\mathbf{4}^{\circ}$ & Elaboração do segundo mapa conceitual (refeito). \\
\hline \hline
\end{tabular}




\subsection{CRITÉRIOS DE ANÁLISES}

Utilizaram-se critérios de análise qualitativa durante a pesquisa para realizar as comparações dos mapas elaborados pelos alunos. Os critérios foram atribuídos de acordo com a elaboração dos mapas criados pelos alunos. Para a análise do conteúdo buscou-se identificar a evolução dos conceitos estudados. Todos os critérios estão apresentados na Tabela 2.

A análise do conceito foi feita da seguinte maneira, os mapas que não apresentavam nenhum conceito relevante ao assunto e que não se relacionavam não era pontuado. Entretanto, para os mapas que se identificavam e se relacionavam, foi atribuída uma pontuação, como está apresentado na Tabela 3.

Tabela 2: Critérios utilizados na avaliação

\begin{tabular}{l|cl}
\hline \hline Critérios & Descrição dos mapas dos alunos \\
\hline Conceito & $\begin{array}{l}\text { Mapas que apresentaram nenhum conceito } \\
\text { relevante; } \\
\end{array}$ & $\begin{array}{l}\text { Conceitos são identificados, mas não se relacionam } \\
\text { necessariamente ao tema do mapa proposto; } \\
\text { Conceitos são identificados e estão de acordo com } \\
\text { o tema do mapa proposto. }\end{array}$ \\
\hline Hierarquização & $\begin{array}{l}\text { Os conceitos trabalhados apresentam-se de forma } \\
\text { ordenada, podendo distinguir os conceitos mais } \\
\text { gerais e o mais específicos mostrando o início de } \\
\text { diferenciação progressiva? }\end{array}$ \\
\hline Relação entre conceitos & $\begin{array}{l}\text { Não existe ligação entre os conceitos mais gerais e } \\
\text { os mais específicos; }\end{array}$ \\
& $\begin{array}{l}\text { Existe ligação entre os conceitos gerais e } \\
\text { específicos e entre os conceitos específicos. }\end{array}$ \\
\hline Clareza ao leitor & $\begin{array}{l}\text { Não existe clareza alguma no mapa ao leitor; } \\
\text { O mapa tem clareza de leitura. }\end{array}$ \\
\hline \hline
\end{tabular}

Na hierarquização foi trabalhada a forma como os alunos organizavam seus conhecimentos, era onde se identificava a diferenciação progressiva do mesmo. A relação dos conceitos era dada da seguinte forma, se o mapa apresentava algum tipo de tipo de ligação entre seus conceitos gerais e específicos era pontuado, caso não apresentasse os termos não pontuava. $\mathrm{E}$ por fim, os mapas que apresentassem clareza e entendimento ao leitor também era pontuado, caso não houvesse clareza e entendimento não pontuava. Tais critérios receberam pontuação conforme dados constantes na Tabela 3.

Tabela 3-Critérios de pontuação

\begin{tabular}{l|l}
\hline Conceito & 2,5 pontos \\
\hline Hierarquização & 2,5 pontos \\
\hline Relação & 2,5 pontos \\
\hline Clareza & 2,5 pontos \\
\hline
\end{tabular}

\section{RESULTADOS E DISCUSSÃO}

Para a discussão dos resultados, os mapas conceituais foram analisados qualitativamente de forma descritiva em função dos critérios de análise (veja Tabela 2) comparativa entre o primeiro e o último mapa conceitual do aluno e, posteriormente, foi reanalisada quantitativa de acordo com os de critérios de pontuações (ver Tabela 3 ). 
Foram elaborados ao todo 56 mapas conceituais, todos feitos pelos 28 alunos participantes da pesquisa, em que cada aluno elaborou 2 mapas. $O$ primeiro mapa proposto aos alunos foi denominado de sondagem, pois através dele puderam-se observar as concepções prévias que eles dominavam sobre tema abordado.

Para discutir os resultados, foram feitas análises qualitativas realizando comparações entre os critérios (conceito, hierarquia, relação entre conceitos e clareza ao leitor) entre o mapa de sondagem e o refeito. A análise será feita com base no referencial teórico, sobre os mapas confeccionados por três alunos, os quais foram denominados: aluno A1, B2 e C3, pois estes demonstraram certo grau de interesse e seriedade, durante toda a pesquisa.

\subsection{ANÁLISE DOS MAPAS DE SONDAGEM}

O primeiro mapa elaborado foi titulado como mapa de sondagem, como o qual, procuramos identificar os conceitos prévios dos alunos sobre o conteúdo de Ondas. Para sua construção, foram apresentadas de forma expositiva, noções básicas dos mapas conceituais, tais como: utilização de conceitos, termos de ligação, ligações transversais e hierarquização.

Os mapas de sondagem demonstraram a falta de aprofundamento do aluno sobre o conteúdo, pois muitos apresentaram apenas conceitos considerados básicos como pode ser observado através da Figura 1, que mostra o mapa elaborado pelo aluno A1. A partir da análise deste mapa, pode-se inferir que o aluno obteve o conhecimento sobre o conteúdo abordado de maneira mecânica que de acordo com Moreira [6], é apenas um assunto de memorização curta, ou seja, que pode ser esquecido rapidamente.

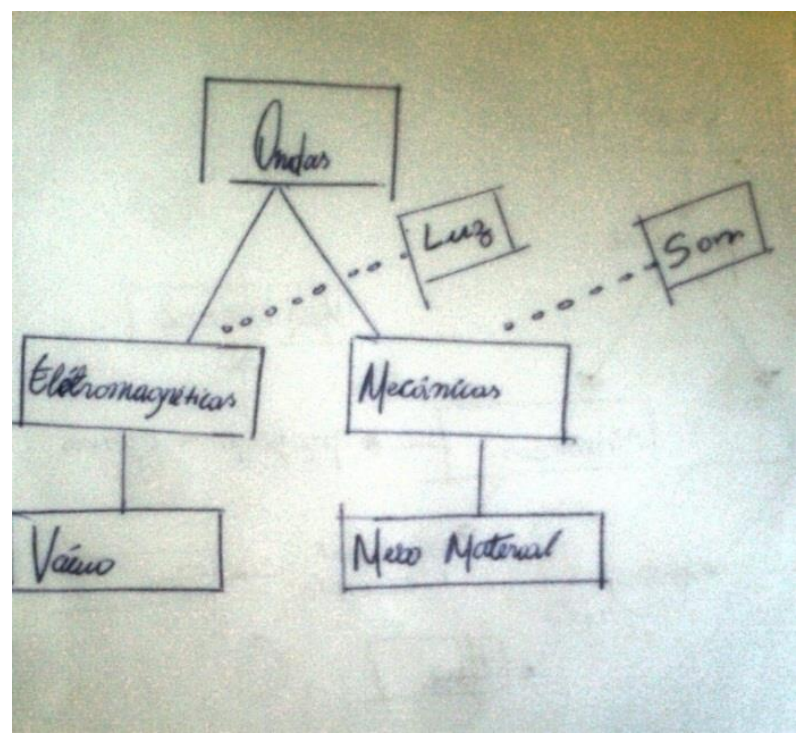

Figura 1: Mapa de sondagem do aluno A1

Após as intervenções didáticas, os discentes desenharam um último mapa, o qual foi construído individualmente. Ao refazer os mapas os alunos foram estimulados a rever e inserir conceitos e termos de ligações, que não constavam nos anteriores. Percebeu-se então, que o último mapa do aluno não é uma mera imitação do primeiro, no geral, significou uma reestruturação conceitual.

Para a construção do segundo mapa, foram apresentadas de forma expositiva, noções básicas dos mapas conceituais, tais como: utilização de conceitos, termos de ligação, ligações transversais e hierarquização.

As maiores dificuldades observadas com relação ao instrumento trabalhado encontraram-se em: organização e estruturação de maneira satisfatória seus mapas conceituais; não utilização dos termos de ligação, tornando o mapa semelhante a fluxogramas e mapa mental; distinção no que seria conceito e o termo de ligação, interligando-os apenas por setas e/ou linhas; e não utilização de conceitos, e sim textos ou definições. A Figura 2, também mostra a ausência dos termos de ligação, tendo em vista apenas uma associação de conceitos e não uma relação entre 
eles, como foi expresso pelo aluno B2. Enquanto que na Figura 3, observamos também que no mapa do aluno $\mathrm{C} 3$, o conteúdo encontra-se básico, ou seja, a falta de aprofundamento e detalhamento do conteúdo, mencionando conceitos que não estavam em questão.

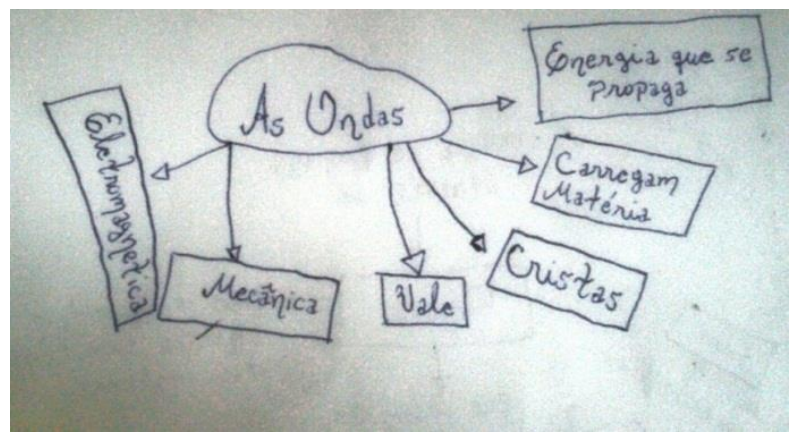

Figura 2: Mapa de sondagem do aluno B2

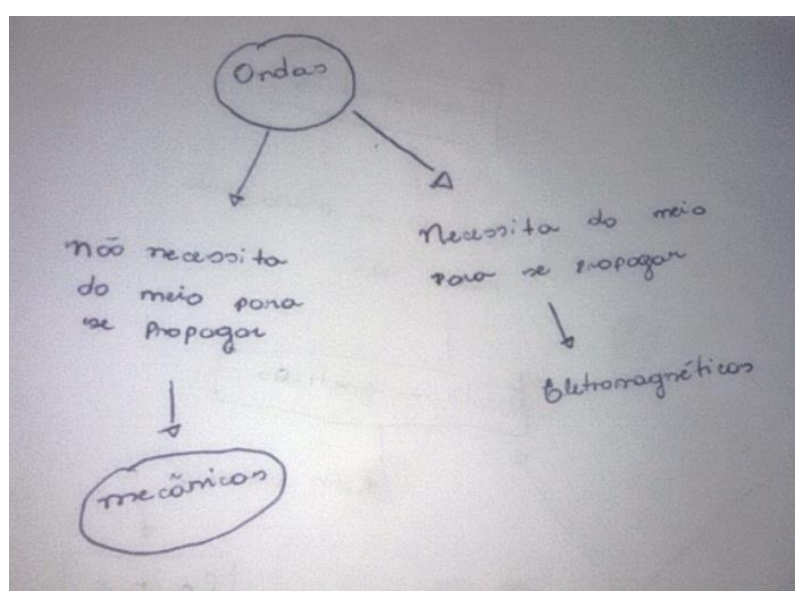

Figura 3: Mapa de sondagem do aluno C3

Observaram-se vários erros nos primeiros mapas e, por isso, foram refeitos adotando o conceito que todos os mapas conceituais devem ser desenhados várias vezes. O primeiro mapa que uma pessoa elabora tem quase sempre falhas e as mesmas apresentam dificuldades. Talvez isso tenha ocorrido, pode fato da dificuldade do aluno mostrar as relações hierárquicas importantes entre conceitos [4]. Para Pacheco e Damásio [17], todas essas dificuldades podem ser atribuídas ao fato de ser o primeiro contato dos alunos com este tipo de metodologia, neste caso o uso do mapa conceitual, a partir da ação de refazê-los, as dificuldades tendem a serem minimizadas e, até mesmo, extintas.

\subsection{ANÁLISES DOS MAPAS REFEITOS}

Após os alunos refazerem seus mapas conceituais, juntamente com a intervenção didática, observou-se em geral uma evolução, tanto na questão da quantidade de conceitos presentes, bem como em conseguiram organizar suas ideias e hierarquizar os conceitos de maneira satisfatória, tornando clara a leitura dos mesmos.

A partir de uma aula de revisão, notou-se o que o conteúdo dos mapas foi mais aprofundado em comparação com o mapa de sondagem, isso mostrou que os alunos buscaram incluir mais conceitos que por sua vez ajudaram na aprendizagem. Por meio, das observações e as análises verificou-se que os alunos conseguiram assimilar o assunto de maneira mais simples e prazerosa. Observou-se também, que a turma apresentou certa dificuldade, porém as mesmas foram reduzidas através do ato de refazer seus mapas. Moreira [20] esclarece que, quanto mais o aluno refazer os mapas, mais ele aprende o conteúdo em questão. Tendo como base esta afirmação, a Figura 4 nos revela um significativo desenvolvimento nos conceitos elaborados pelo aluno A1. No mapa apresentado nesta figura, percebe-se a hierarquização entre os conceitos gerais, e os específicos passaram a ser constatado, consequentemente, gerando a 
ocorrência da diferenciação progressiva no mapa. O mesmo pode ser explicado durante o processo da aprendizagem significativa, quando o indivíduo diferencia os conceitos ou muda seus significados e os especifica, consequentemente estará diferenciando-os progressivamente, ou seja, tornando mais ricos seus significados e facilitando o aprendizado.

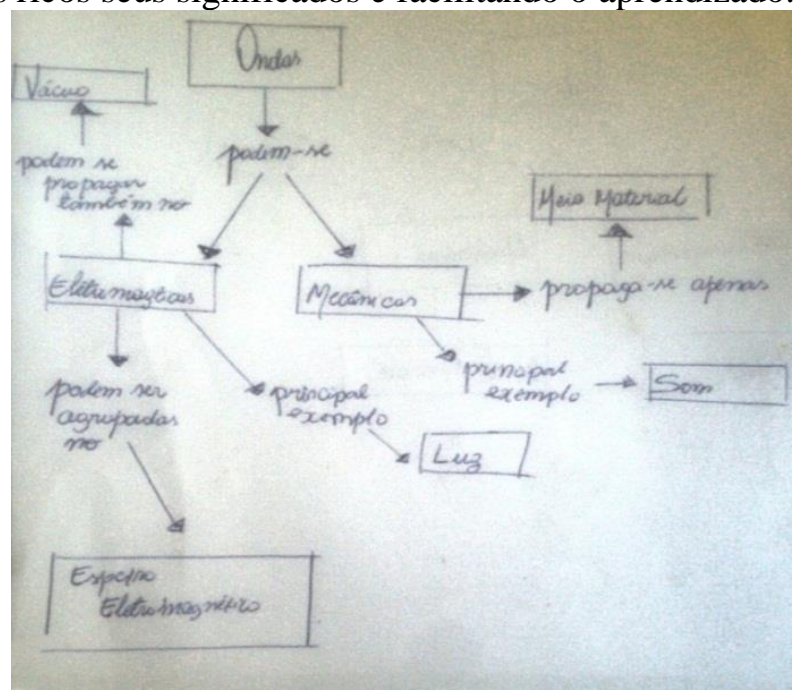

Figura 4: Mapa refeito do aluno Al

Outro avanço verificado nos mapas dos alunos durante o processo de aprendizagem foi o entendimento correto de construção de mapa conceitual, diminuindo a elaboração de mapas mentais que, após a intervenção didática, o mapa dos mesmos (por exemplo, aluno B2) tornouse mais claro e hierárquico e, as relações existentes, mostraram-se significativas como pode ser observado na Figura 5 a seguir.

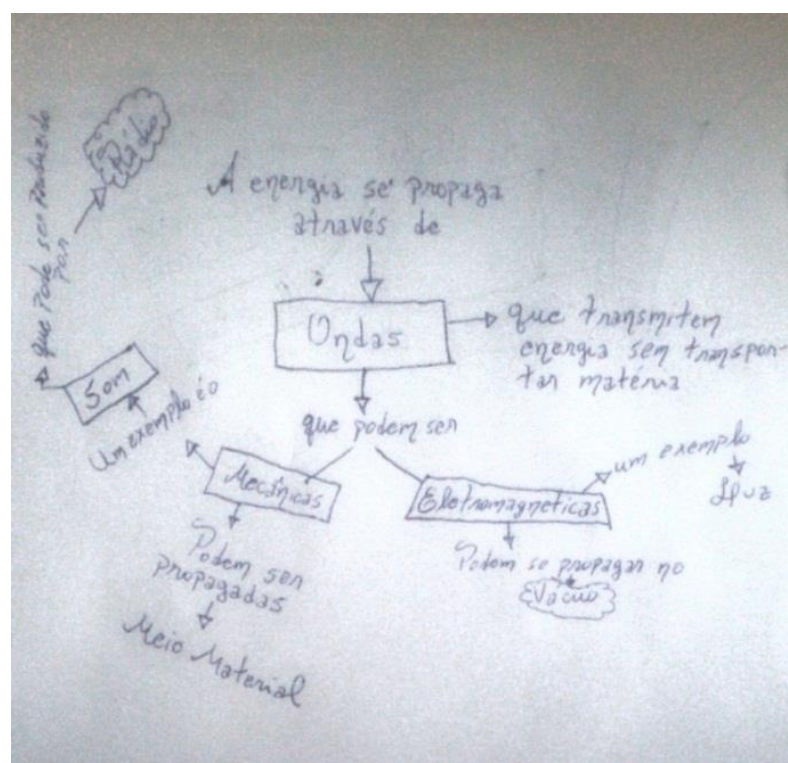

Figura 5: Mapa refeito do aluno B2

O uso de definições ou pequenos textos também foi minimizado. Por outro lado, em detrimento da utilização de conceitos com clareza, pode-se inferir que os conceitos sobre o conteúdo foram sendo estruturados e organizados no senso cognitivo do aluno, como pode ser claramente visualizado na Figura 6. 


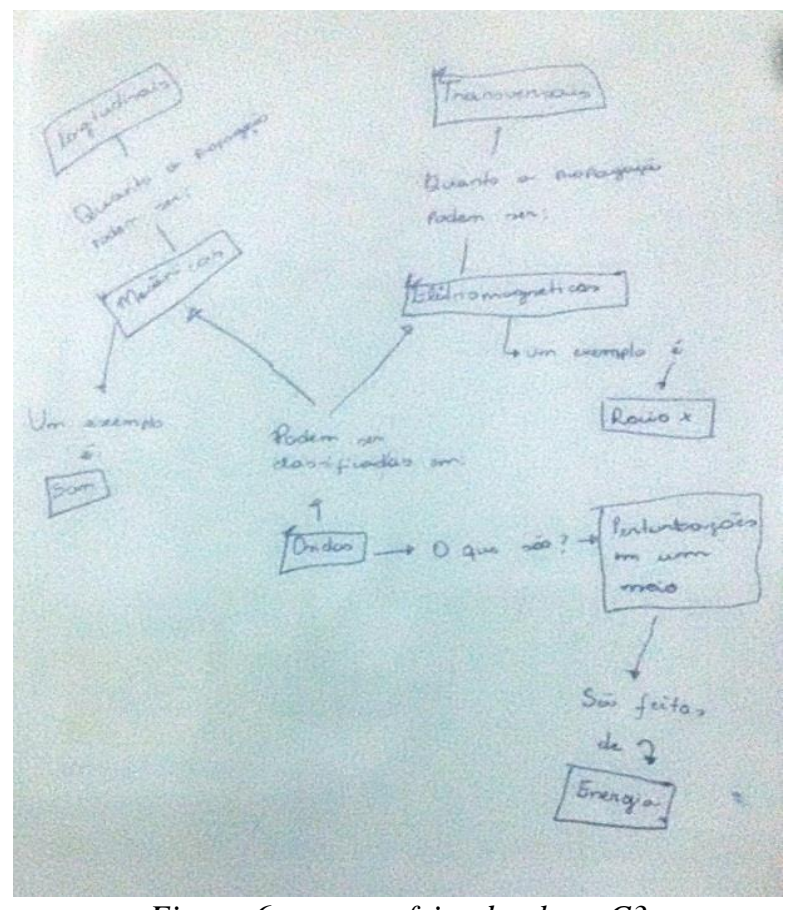

Figura 6: mapa refeito do aluno $C 3$

\section{CONCLUSÕES}

O trabalho foi desenvolvido para avaliar os conhecimentos dos alunos com o uso de mapas conceituais. Além disso, buscou-se uma aprendizagem significativa para os alunos, uma vez que $o$ instrumento funciona como um organizador do conhecimento. Alguns dos alunos demonstraram resistência ao novo método e a forma como iriam ser avaliados. Isso talvez esteja relacionado ao fato da maioria dos alunos terem sido "moldados" desde cedo com a metodologia tradicional, onde o professor passa o conteúdo e estes apenas memorizam e transcrevem em provas/testes. Contudo, a ideia em construir os mapas foi inserida aos poucos como uma atividade avaliativa. À medida com que os alunos refaziam os mapas, foi possível constatar novos conceitos inclusos, o que foi constatado quando comparamos aos seus primeiros mapas conceituais. Também foi observado como o conteúdo encontra-se estruturado e organizado no senso cognitivo deles. Desse modo, a construção dos mapas conceituais permitiu avaliar o desenvolvimento do aluno, mostrando ser importante descobrir o que o aluno aprendeu e poder acompanhar o processo de construção desse conhecimento. A utilização dos mapas conceituais como instrumento de avaliação, mostrou-se válida, quando contribui para a organização de ideias e a possibilidade de integração dos conhecimentos prévios dos alunos com os novos conhecimentos.

\section{AGRADECIMENTOS}

Nossos agradecimentos à Escola Municipal Dr. José Cursinho de Azedo (Marabá-Pará) e à Universidade Federal do Sul e Sudeste do Pará-UNIFESSPA.

\section{REFERÊNCIAS BIBLIOGRÁFICAS}

1. Bessa VH. Teorias da Aprendizagem. - Curitiba: IESDE Brasil S.A., 2008.

2. Prass AR. Teorias De Aprendizagem. ScriniaLibris.com, Rio Grande do Sul; 2012. 28 p.

3. Ausubel DP. Educational psychology: a cognitive view. New York: Holt, Rinehart and Winston, 1968.

4. Novak JD. Aprender a aprender. $1^{\circ}$ Ed, Paralelo, 1984.

5. Bachelard G. Epistemología. Barcelona: Editora Anagrama. 1971, p. 254.

6. Moreira AM. Teorias de aprendizagem. 2. ed. São Paulo: Editora pedagógica universitária Ltda, 2011. 
7. Skinner BF. Tecnologia do ensino. (Rodolpho Azzi, Trad.). São Paulo: Herder, Ed. da universidade São Paulo, 1972.

8. Vygotsky LS. Pensamento e Linguagem. São Paulo: Martins Fontes, 1998.

9. Pelizzari A, Kriegl ML, Baron, MP, Finck NTL, Dorocinski SI. Teoria da Aprendizagem Significativa segundo Ausubel. Revista PEC, Curitiba, 2002, p. 37-42.

10. Tavares R. Aprendizagem significativa. Revista conceitos - N55; 2004.

11. Novak J, Cañas A. A teoria subjacente aos mapas conceituais e como elaborá-los e usá-los. Práxis Educativa, Ponta Grossa, 2010, p. 9-29.

12. Araújo MST, Abid MLVS. Atividades experimentais no ensino de Física: Diferentes enfoques, diferentes finalidades. Revista Brasileira de Ensino de Física 2003 junho;25(2):176-194.

13. Goncalves CL, Pimenta SG. Revendo o ensino de $2^{\circ}$ grau: propondo a formação de professores, 2ed. São Paulo: Cortez, 1992.

14. Santos EI, Piassi LPC, Ferreira NC. Atividades Experimentais de baixo custo como estratégia de construção da autonomia de professores de Física: uma experiência em formação continuada. In: IX Encontro Nacional de Pesquisa de Física. Belo Horizonte, 2004.

15. Libânio JC. Didática. 13 Ed. São Paulo, Cortez, 1994.

16. Novak JD, Results and Implications of a 12-Year Longitudinal Study of Science Concept Learning. Research in Science Education 2005 March;35(1): 23-40, doi: 10.1007/s11165-004-3431-4

17. Pacheco SMV, DamasiO F. Mapas conceituais e diagramas V: ferramentas para o ensino, a aprendizagem e a avaliação no ensino técnico. Ciências \& Cognição, Araranguá - SC 2009 julho;14(2): 166-193.

18. Turns J, Atman CJ, Adams, R. Concept Maps for Engineering Education: A Cognitively Motivated Tool Supporting Varied Assessment Functions. IEEE Transactions on Education 2000 may; 43(2): 164-173, doi: $10.1109 / 13.848069$

19. Moreira MA. Mapas Conceituais, diagramas V e Organizadores Prévios. ed. 1. Porto Alegre; 2016 p. $1-71$. 